Published in final edited form as:

Behav Genet. 2007 March ; 37(2): 284-293.

\title{
Focus on Words: A Twin Study of Reading and Inattention
}

\author{
Allison Zumberge, \\ Neuroscience Graduate Program, University of Southern California, Hedco Neurosciences Building, \\ Los Angeles, CA 90089-2520, USA e-mail: azumberg@usc.edu \\ Laura A. Baker, and \\ Neuroscience Graduate Program, University of Southern California, Hedco Neurosciences Building, \\ Los Angeles, CA 90089-2520, USA; Department of Psychology, University of Southern California, \\ Los Angeles, CA 90089-2520, USA
}

Franklin R. Manis

Neuroscience Graduate Program, University of Southern California, Hedco Neurosciences Building, Los Angeles, CA 90089-2520, USA; Department of Psychology, University of Southern California, Los Angeles, CA 90089-2520, USA

\begin{abstract}
The etiology of variation in reading ability and its relationship to inattention, impulsivity, and general cognitive ability were investigated within a large, population-based sample of 9- to 10-year-old twins. Phenotypic and genetic analyses were performed on word-level reading, full-scale IQ, and measures of inattention and impulsivity derived from the Go-7NoGo task (i.e., Go errors and NoGo errors, respectively). Moderate and significant phenotypic correlations were found among reading, inattention and IQ, but not between impulsivity and the other variables. Genetic modeling revealed that genetic and shared environmental influences largely accounted for variation in reading, inattention, and IQ and covariation among them, whereas specific environmental influences contributed primarily to variation in impulsivity. Acting through a common factor, a portion of the genetic influences on reading ability appeared to be shared with influences affecting IQ as well as those affecting inattention. The contribution of phonological awareness to the remaining unique genetic influences on reading was explored through additional analyses. A two-common-factor model was revealed, with a strongly genetic general cognitive ability factor affecting reading, inattention, and IQ, and an equally strongly genetic second common factor, which captured the variability in reading ability that was related specifically to phonological processing. The processes involved in reading, therefore, seem to involve genetic and environmental influences that are part of both a general cognitive system and a system more specific to reading and phonology.
\end{abstract}

\section{Keywords}

Reading ability; Inattention; Behavior genetics

\section{Introduction}

Reading is a complex process that requires the coordination of numerous cognitive abilities. General cognitive ability, sometimes considered synonymous with IQ, is principal among the requirements. Other integral components of reading are command of language abilities (verbal IQ), phonological awareness, working memory, and attention (Gayan and Olson

2001; Swanson and Berninger 1996;Commodari and Guarnera 2005). However, the overlap

\footnotetext{
Correspondence to: Allison Zumberge.
}

Edited by John Hewitt 
between the contributions of these components is not clear, and the etiological and developmental relationships among the components have not yet been fully delineated.

Numerous studies have investigated the proportion of variance in reading ability that is explained by the different components, especially IQ (Harlaar et al. 2005), and family and twin studies have suggested genetic influences on some of the factors separately (Gayan and Olson 2003). Inattention has been the focus of some research inspired by the clinical comorbidity of deficits in reading and attention (Willcutt et al. 2000,2005). But few studies have attempted to illuminate the relationship between normal variation in reading and inattention. The aim of the present study was to investigate (a) the correlation between individual differences in reading ability, IQ, and inattention, and (b) the individual and common genetic and environmental bases of normal variation in these cognitive traits.

Behavior genetics studies have established that genetic influences on most cognitive abilities are overlapping (Plomin and Craig 2001). A genetic relationship between one such ability, reading, and IQ, a very broad assessment of cognitive skills, is therefore not surprising. More than half of the strong phenotypic correlation between reading and IQ, which ranges from 0.4 to 0.7 (Grigorenko 2001), is due to genetic influences (Harlaar et al. 2005; Wainwright et al. 2004; Gayan and Olson 2003; Tiu et al. 2004). This relationship is stronger for verbal IQ than performance IQ (Brooks et al. 1990; Cardon et al. 1990).

However, as with other cognitive abilities, reading has an etiology that is not completely dependent on shared genetic influences with IQ. Three fourths of the individual differences in reading are influenced by genes independent of general cognitive ability (Harlaar et al.

2005). IQ is not often used in practice as a predictor of reading ability because of the existence of children with low IQ but average reading ability, or of children with dyslexia, the latter of which has a cognitive profile that often includes a discrepancy between reading level and IQ. This implies that factors other than IQ are critical to the development of successful reading abilities.

Contributions by other factors are made clear by considering the complexity of the task. Verbal comprehension, executive functioning, and working memory are abilities necessary for many complex cognitive tasks, such as reading (Berninger et al. 2006). Skills more specific to reading include phonological and orthographic knowledge (Sprenger-Charolles et al. 1998;Ehri and

Wilce 1985). In order to recognize words, one must possess a knowledge of individual sounds and their correspondence to letters. In the case of words which have unusual or unpredictable "grapheme-phoneme correspondences" (GPCs), one must rely on other sources of information, such as word-specific orthography or semantic context, to figure out the word. Findings from Gayan and Olson (2003) indicate that word recognition skills are significantly heritable (51\% from additive genetic influences, and 38\% from non-additive), as are the component processes associated with word recognition: phonological awareness (PA) (77\% additive) and orthographic coding (OC) (72\% non-additive), as measured by wordpseudohomophone or homonym differentiation tasks (Olson et al. 1989). The underlying components of these reading-specific skills involve visual and auditory information processing, which can be thought of as bottom-up processes, although top-down processes in word recognition exist as well (such as use of context; West and Stanovich 1982).

Attention ought to also play a critical role in successful reading skills, as it "governs the flow" of cognitive processes such as perception and memory (Cohen et al. 1998). Allocation of attention, also termed "focus" or "selective attention," implies withdrawal from competing information, such as distractors or other cognitive tasks, for efficient performance on the task at hand (Weiler et al. 2002). Sustained attention refers to consistent focused attention over time and is certainly an important component of reading. Limitations in the capacity for either of 
these types of attention can interfere with reading performance, as well as reading development. The interference can also work in the opposite direction; poor word recognition can make attention wander in group reading situations (Aaron et al. 2004). Commodari and Guarnera (2005) found that adolescents who performed poorly on passage reading tests also performed poorly on a test of immediate attention span. No genetically informed study of which we are aware has provided a link between word reading ability and inattention within a representative sample. A genetic link has been made, however, between inattention and IQ; Kuntsi et al. (2004) reported a negative phenotypic correlation between IQ and Attention Deficit Hyperactivity Disorder (ADHD) symptoms $(r=-0.3)$ that was largely due to shared genetic etiologies (86\%). The ADHD measure was a composite score, but the authors observed that "the genetic relationship with IQ was similar across the different symptom dimensions."

Attention is a construct that is difficult to define operationally. It is perhaps for this reason that the primary attempts to clarify its relationship with reading focus on deficits of attention and deficits of reading, namely ADHD and reading disability (RD), respectively. Based on their prevalence rates of about $5 \%$ each, diagnoses of these two disorders co-occur more often than expected by chance, with a comorbidity rate in the range of 15-30\% (Shaywitz et al. 1992). Searching to explain this high comorbidity, Willcutt et al. (2001) described the "cognitive underpinnings" of the disorders; low PA is the core deficit in children who are reading disabled, whereas poor performance on executive function (EF) tasks characterizes children with ADHD. The comorbid group performed worst on almost all PA and EF tasks, providing evidence against the phenocopy hypothesis of RD and ADHD, which posits that the primary disorder causes the symptoms of the other (Willcutt et al. 2001).

The cause of the comorbidity probably lies further down the line; behavioral genetics studies have suggested that it may be attributable to genetic influences that are shared between the disorders, both of which seem to be over 50\% heritable (Gillis et al. 1992;Schulte-Korne 2001). The three hypothesized subtypes of ADHD, inattentive, hyperactive/impulsive, and combined type (APA 1994;Barkley 1998), do not seem to have equal genetic overlap with RD, however. Previous studies have shown stronger phenotypic and genetic relationships between $\mathrm{RD}$ and symptoms of inattention. Whereas $95 \%$ of the phenotypic covariance between RD and inattention symptoms is due to common genetic influences, the genetic influences common to $\mathrm{RD}$ and hyperactivity/impulsivity symptoms account for only $21 \%$ of their covariance (Willcutt et al. 2000).

Reading occurs along a continuum, with RD representing only the tail end of the normal curve (Shaywitz et al. 1992), and there is no reason not to assume that attention varies similarly. If attention appears to be a component of reading at one end of the curve, the relationship may exist across the continuum, as well. Little work has been done investigating normal variation in the relationship between reading and attention. Also, little work has been done using formal measures of inattention and impulsivity instead of symptom counts.

Given the links among reading, IQ, and inattention, it seems reasonable that these three may share some etiological influences. The present study aimed to clarify the core genetic and environmental influences on the relationships among the three dimensions by means of a twin study. Laboratory measures of IQ, reading, inattention, and impulsivity from MZ and DZ twins were fit to models to reveal unique and common genetic and environmental influences on the cognitive constructs. Twins' scores on verbal and performance IQ subtests were combined into a measure of full-scale IQ. The word reading measure was also a composite score, comprised of performance on tests which assessed the child's ability to pronounce isolated real words and non-words. Inattention and impulsivity were assessed through the Go-NoGo task, which is a variation of a continuous performance task (CPT) and widely used in studies of executive functioning (Fischer et al. 2005; Hansen et al. 2003; Corkum and Siegel 1993). 
The purpose of the study was to examine phenotypic and genetic relationships between the measures to understand the full range of variation in reading and its component processes, including IQ and inattention, as well as etiology. To what extent do the abilities reflect distinct genetic components, and which genetic components are shared? Based on the genetic overlap between reading and attention disorders, we hypothesized that the reading measure would have a greater genetic overlap with the inattention measure than it would with the impulsivity measure, and that this relationship would hold up even after accounting for IQ.

\section{Methods}

\section{Participants}

The present study is based on 605 sets of identical (monozygotic, MZ) and fraternal (dizygotic, DZ) 9- and 10-year-old twins and triplets (mean age $=9.60, \mathrm{sd}=0.58$ ) who participated in a larger study of behavior problems at the University of Southern California (see Baker et al. 2007 for a detailed description of the sample recruitment and larger study). Subjects were recruited from the Los Angeles community, and the sample is representative of the ethnic and socio-economic diversity of the greater Los Angeles area. Ethnic breakdown of the twins was 26.6\% Caucasian, non-Hispanic, 37.5\% Hispanic, 14.2\% Black, 4.5\% Asian, and 17.2\% Mixed/Other. All subjects were fluent English speakers. The present sample consisted of 277 MZ twin pairs (139 male and 138 female) and $328 \mathrm{DZ}$ twin pairs ( 84 male, 97 female, and 147 male-female). Twins were randomly assigned as Twin 1 and Twin 2, with the exception of male-female pairs, where the male was always coded as Twin 1.

\section{Measures}

Participants were administered a large assessment battery (7-8 h) at the University of Southern California. The assessment was divided into two sessions, separated by a 1-h break. The neurocognitive measures, of which the present tasks are a subset, were administered individually to each child. The trained examiners were paid staff members or students.

Reading ability was measured by two different tasks from the Woodcock-Johnson Tests of Achievement (Woodcock and Mather 1989), Letter-Word ID and Word Attack, which had subjects read aloud rows of increasingly difficult words and pseudowords, respectively, until they reached an error criterion. Scores on these tasks were highly correlated $(r=0.80, p<$ 0.001 ) and so were standardized and averaged to produce a composite score of reading ability that estimated both orthographic knowledge and phonological ability. A measure of phonological awareness, Elision, was also included in the test battery and was used in the second set of analyses. The Elision task (Comprehensive Tests of Phonological Processing; CTOPP; Wagner et al. 1999) required the subject to repeat a word without a specified phoneme (e.g., "split" without the "l" sound would become "spit").

IQ was evaluated by the Wechsler Abbreviated Intelligence Scale (WASI; Wechsler 1996). Full-scale IQ (FIQ) was estimated by combining scores on two subtests that measure verbal IQ (Vocabulary and Similarities) and two that measure performance IQ (Block Design and Matrices). Only the combined FIQ score was analyzed in the present study.

Inattention and impulsivity were measured by the Go-NoGo task, a variation on the CPT, which requires sustained attention. Pure tests of attention do not exist; all tasks that require sustained or selective attention also measure one or more other cognitive abilities, such as processing speed. Although its "ecological validity as a measure of ADHD" is controversial (Willcutt et al. 2001), CPT is often used as a tool in ADHD diagnoses. We consider the Go-NoGo task used in the present study to be a valid though imperfect measure of overall inattention. One advantage of the Go-NoGo task is that different dimensions of performance can be used to 
assess individual abilities. In the Go-NoGo task used in the present study, the subject was required to watch a sequential presentation of letters and respond only to the target letter by pressing a button. The ratio of target letters to non-target letters was designed to establish a strong positive response set, and the task was therefore aimed at measuring inhibitory control. The two core symptoms of ADHD were assessed by behavioral performance on the different components of this task: a high rate of NoGo errors ("false alarms," responding to a non-target letter) is typically considered an indicator of impulsivity, whereas frequent Go errors ("misses", or failures to respond to a target letter) are considered to be an indicator of inattention to the task (Bezdjian et al. 2007, unpublished manuscript; Barkley 1991;Halperin 1991). Go and NoGo errors were used in the present study as measures of inattention and impulsivity, respectively.

Reliability of the measures in the present study was evaluated using test-retest correlations for a subset of 30 families ( $n=60$ children) who participated in an identical re-assessment 6 months following their initial laboratory assessment, as well as through split-half methods for the full sample. Six month test-retest correlations were moderate to high and statistically significant (all $p$-values $<0.05)$ for the reading composite $(r=0.88)$, the CTOPP Phoneme Elision test $(r=0.66)$, IQ $(r=0.85)$ and both the Go errors $(r=0.51)$ and NoGo errors $(r=0.66)$. Go errors and NoGo errors were also significantly correlated between the first and second half of the trials ( $r=0.69$ and $r=0.74$, respectively). Thus, the primary measures in this study demonstrate both internal consistency and repeatability over a six-month period.

\section{Genetic modeling}

Multivariate genetic models were applied to the data, using Mx software (Neale et al. 2003), to test for common and independent genetic and environmental influences on reading, IQ, inattention, and impulsivity. Based on observed variances and covariances among the twin pairs, these structural equation models allowed us to estimate contributions to individual differences in these variables from three sources: additive genetic effects (A), shared environment $(\mathrm{C})$, and non-shared environment $(\mathrm{E})$. Initial analyses were performed on measures of IQ, Inattention (Go errors), Impulsivity (NoGo errors), and Reading (the composite of Letter Word Identification and Word Attack subtests). A series of models was fit to raw scores, beginning with a saturated model to estimate the means and the $8 \times 8$ matrices of covariances among the four variables in the twin sets. A saturated model with means constrained to be equal across co-twins and zygosity groups (which did not differ significantly from the fully saturated model without mean constraints) served as a basis for comparison of all subsequent models. Additional models fit included (1) a general Cholesky model, with no specified factor structure among the four phenotypes; (2) independent pathway models, including one or two factors influencing the four phenotypes; and (3) common factor models, including one or two factors exerting common influences on the four variables, in addition to specific genetic and environmental influences. Sex differences were also tested in the Cholesky model, but were not found to be significant and thus were not evaluated in subsequent multivariate genetic analyses. The best-fitting and most parsimonious model was determined by selecting the smallest value of Akaike's Information Criterion (AIC; Akaike 1987) among the alternative models.

\section{Results}

Distributions of reading, IQ, and impulsivity measures were approximately normal, while achieving a normal distribution of Go errors required a square-root transformation of the raw scores. Correlations between variables are presented in Table 1 . Reading was significantly correlated with IQ $(r=0.57 ; p<0.05)$ and negatively correlated with the number of Go errors (Inattention; $r=-0.26 ; p<0.05$ ) but not with the number of NoGo errors (Impulsivity; $r=$ 
-0.04 ; ns). One would therefore not expect to find significant genetic overlap between impulsivity and reading. Inattention and impulsivity showed a small but significant correlation $(r=0.07 ; p<0.05)$. This low correlation supports the assumption that Go and NoGo errors tap into relatively distinct aspects of attentional control.

Comparison of MZ and DZ twin correlations, in Table 2, provided rough indications of genetic influences on the variance of each measure, since MZ twins share all of their genes, while DZ twins share only half. With the exception of Elision, all of the variables were clearly more highly correlated among MZ twins than DZ twins, suggesting some heritability.

A more statistically powerful approach, structural equation modeling, provided further information on the genetic and environmental influences. Univariate analyses quantified the genetic and environmental influences on the variables individually, based on observed variance. They estimated a heritability of 39\% for IQ, $46 \%$ for Inattention, and $70 \%$ for Reading, meaning that individual differences in IQ, inattention, and reading ability are substantially influenced by genetic factors. Univariate analyses also revealed a heritability of $22 \%$ for Impulsivity (See Table 2 for genetic and environmental parameter estimates from Univariate models). Multivariate analyses were conducted to estimate genetic and environmental variance common across the variables. Model fit comparisons are presented in Table 3. Cholesky decompositions fit the data as well as the saturated model, and equating variance components across the sexes did not result in a significantly worse fit. Thus, the same genetic and environmental influences contribute equally in boys and girls to individual differences in IQ, inattention, impulsivity, and reading, and all subsequent models that were tested specified no sex differences. The most parsimonious model was a one-common-factor model (Model 6), which posited a single latent construct as the source of the genetic and environmental influences that are common to the variables.

As seen in Fig. 1, the common factor was largely and significantly influenced by genes $\left(0.80^{2}=0.64\right)$ and shared environment $\left(0.57^{2}=0.32\right)$. Non-shared environment was not a significant source of variance in the common factor $\left(0.17^{2}=0.03\right)$ and thus did not account for underlying covariance among these measures. Factor loadings were significant and moderately high for all variables with the exception of Impulsivity, indicating that the common factor accounted for a substantial portion of the variance in IQ and reading and a moderate portion of the variance in inattention. Impulsivity did not appear to be related to the other variables through the common factor, as indicated by an insignificant factor loading $(-0.06)$. Factor loadings can be used to estimate the total heritability due to the common factor by multiplying the squared loading with the squared parameter estimate for the common genetic factor, "A." (Total effects of shared and non-shared environmental influences can be estimated in the same way.) The heritability which is not due to the common factor is indexed by the squared value of the unique genetic influence, "a" in Fig. 1. The sum of these genetic components equals the total heritability of each variable. In the case of IQ, the common factor accounted for all of its heritability $\left(0.80^{2} \times 0.64=0.41\right)$; none was independent of the other variables $\left(0.10^{2}=0.01\right)$. The breakdown of common and unique influences on each variable is provided in Table 4. In the case of Reading, the heritability was due in equal parts to common and unique genetic influences. Impulsivity shared no common factors with the other variables, as indicated by zero values under Common A, C and E. Finally, the common influences on Inattention were greater than zero, but most influences on Inattention were unique. The moderate genetic influences specific to each of Reading (31\%) and Inattention (36\%) are particularly noteworthy, since they suggest genetic contributions to reading and inattention that are independent of general cognitive ability.

Additional analyses were conducted to elucidate the nature of this specific genetic contribution to Reading in particular. Hypothesizing that this unique contribution could be related to aspects 
of phonological ability that are independent of IQ, we performed a second set of genetic analyses for Reading, Inattention and IQ, with the addition of a phonological awareness measure (CTOPP Phoneme Elision). Removing the Impulsivity measure did not worsen the fit of the first model, thus we did not include this measure in the second set of analyses. Phenotypic correlations were moderate to high between Elision and the reading composite $(0.61, p<0.01)$, between Elision and IQ $(0.49, p<0.01)$, and also significant between Elision and Inattention $(-0.20, p<0.01)$. Univariate analyses estimated a heritability of $52 \%$ for Elision. The same series of multivariate models were fit to the four variables as in the first set of analyses, followed by a few additional models to test for significance of specific parameters. The best-fitting model was a two common-factor model, with the first factor loading on all four variables (IQ, Inattention, Reading, and Elision) and a second factor, which loaded on only Reading and Elision (Table 5 and Fig. 2). The most parsimonious version of the model forced the unique genetic contributions to both Reading and Elision to be zero. The first factor was interpreted to be a general cognitive ability factor; it loaded significantly on all four measures and accounted for all of the genetic influences on IQ. The second factor was best interpreted as Phonological Awareness, which contributed genetic and environmental (largely non-shared) influences to both Reading and Elision. No additional specific genetic influences on Reading remained after accounting for these two factors. This model thus indicates that the variation in reading in the present study was largely due to genetic and environmental influences that were shared with IQ, attention, and phonological awareness. The smaller loading of the second order PA factor on Elision, as compared to Reading, and the larger unique non-shared environmental influence on Elision suggests that there is untapped experiential (and possibly method-specific) variance in the Elision variable. It is notable that a fairly substantial unique genetic influence on Inattention was obtained in this model, suggesting that additional unmeasured genetic influences on Go errors might exist.

\section{Discussion}

This study was motivated by the current lack of information on the etiologies of reading and attention, and the relationship between the two domains. Unlike previous studies which have investigated this relationship using disabled populations (children with RD and/or ADHD), we were interested in describing the relationship between normal variation in reading and attention abilities. We therefore used a large, representative sample of 9- and 10-year-old twins, whose scores on reading, IQ, and inattention measures varied widely. Although age is an additional factor that can illuminate developmental processes and should be included in future, longitudinal studies, the present study's use of a sample with a narrow age range allowed for a focus on the relationships at a single point in development. Genetic modeling revealed that genetic influences contributed substantially to variation within the abilities, as well as to covariation among them. Acting through a common factor, a portion of the genetic influences on reading ability appeared to be shared with those affecting IQ, consistent with other findings (Harlaar et al. 2005; Wainwright et al. 2004;Gayan and Olson 2003; Tiu et al. 2004), as well as genetic influences on inattention and phonological ability (but not on impulsivity). This factor was strongly genetic, but also included a fairly substantial shared environmental contribution. A second common factor, which was also strongly genetic, captured the phonological part of reading, a finding which supports previous evidence of an important role for phonological processes in influencing reading ability (Hayiou-Thomas et al. 2006; Wagner et al. 1997; Gayan and Olson 2001). The phonological common factor had a moderate non-shared environmental influence on Reading and Elision. This additional information led us to label the first latent factor "g" for general cognitive ability and the second "PA" for phonological ability. The processes involved in reading, therefore, seem to involve genetic and environmental influences that are part of both a general cognitive system and a system more specific to reading and phonology. 
The large estimate of unique environmental influences (E) on Impulsivity merits some discussion, as this pattern often implies measurement error. We do not reject this possibility, although we note that this measure showed considerable stability over a six-month interval $(r=0.66)$, as well as a strong test-retest correlation $(r=0.74)$. Thus, $\mathrm{E}$ is not likely to be completely explained by measurement error. The lack of heritability for Impulsivity found by the present study is consistent with previous studies that investigated inattention and impulsivity using task measures (Holmes et al. 2002; Heiser et al. 2006; Groot et al. 2004). At least one study, however, reports significant genetic influences on event-related potential components associated with NoGo errors (Anokhin et al. 2004). Further work is needed to confirm the present findings on the proportion of variance in inattention that is associated with genetic influences, shared environment and unique environment.

It has been suggested previously in studies of individuals with comorbid reading difficulties and ADHD that the etiological relationship between reading and inattention is stronger than that between reading and impulsivity (Willcutt and Pennington 2000). The present findings are consistent with this hypothesis, and they provide further details about the etiology of the relationship. Whereas inattention and reading ability share genetic influences, impulsivity and reading ability do not overlap in genetic or environmental influence.

A further point of consideration with regard to RD and ADHD co-morbidity in light of the present findings is the portion of genetic influences on reading that is independent of inattention. One can generalize from this finding within a representative sample that reading disability and inattention have two independent sources of deficiency. Inattention appears to have unique genetic influences that do not overlap with general cognitive and specific phonological influences on reading. This finding suggests there may be multiple subtypes or variants of RD. Some children may be poor readers because they are generally low in cognitive ability ("g"), others may have specific phonological problems (classic dyslexic cases), and still others may have a combination of the preceding two factors and inattention.

What is attention and what makes it related to reading? We have provided evidence that inattention shares genetic variation with reading ability and IQ through a general cognitive factor, so it is possible that inattention (as measured by Go errors) is related to executive functioning, which in turn may have broad influences on IQ test performance. Additional studies exploring the contribution of executive functions to the present measures of reading and attention would be valuable.

Implications arise from the differences between the two factors loading on reading. Whereas the " $\mathrm{g}$ " factor is almost completely defined by genetics and common environment, the PA factor has both a genetic and a fairly substantial non-shared environmental component. With regard to the latter, it has been argued that reading instruction does influence phonological ability and vice versa (Hayiou-Thomas et al. 2006). We can speculate that the two-way instructional influence is captured by the non-shared environment component of the PA factor (because many of the siblings are probably responding to somewhat different instructional environments). It would follow that, even in the normal population, phonological ability instruction is beneficial as a training boost to reading ability, and vice versa. The unique environment component of the PA factor may also reflect the importance of and great variability in early reading instruction. Reducing variability in instruction, i.e., implementing more uniform, high-quality reading programs, may result in reduced variability in reading abilities.

Future work may be motivated by the interesting specific influences on inattention. Also, given the genetic overlap between reading, IQ, and inattention, it would be interesting to pursue QTL analyses to test for candidate genes in IQ and inattention domains as possible markers of RD. 
By employing the bivariate linkage method, some studies have pinpointed many genetic loci with possible pleitropic effects on RD and ADHD (e.g., Willcutt et al. 2002;Gayan et al. 2005). Consistent with the present study, in addition to the QTLs in common with ADHD are those that are unique to reading (Loo et al. 2004), which one might speculate are linked to phonological processes.

\section{Acknowledgements}

The authors wish to thank the USC twin project staff for assistance in data collection and scoring, and the twins and their families for their participation in this research. This study was supported by a grant to the second and third authors from the International Dyslexia Society, and by a grant to the second author from the National Institute of Mental Health (R01 MH58354).

\section{References}

Aaron PG, Joshi RM, Phipps J. A cognitive tool to diagnose predominantly inattentive ADHD behavior. Journal of Attention Disorders 2004;7:125-135. [PubMed: 15260170]

Akaike H. Factor analysis and AIC. Psychometrika 1987;52:317-332.

American Psychiatric Association. Diagnostic and statistical manual of mental disorders. 4. Author; Washington, DC: 1994.

Anokhin AP, Heath AC, Myers E. Genetics, prefrontal cortex, and cognitive control: a twin study of event-related brain potentials in a response inhibition task. Neurosci Lett 2004;368:314-318. [PubMed: 15364418]

Baker LA, Barton M, Raine A, Fowler J. The Southern California Twin register at the University of Southern California: II. Twin Res. 2007in press

Barkley RA. The ecological validity of laboratory and analogue assessment methods of ADHD symptoms. J Abnormal Child Psychol 1991;19:149-178.

Barkley, RA. Attention-deficit hyperactivity disorder: A handbook for diagnosis and treatment. 2. Guilford; New York: 1998.

Berninger VW, Abbott RD, Thomson J, Wagner R, Swanson HL, Wijsman EM, Raskind W. Modeling phonological core deficits within a working memory architecture in children and adults with developmental dyslexia. Sci Stud Read 2006;10:165-198.

Bezdjian S, Baker L, Lozano DI, Raine A. Attention and impulsivity in the Go-NoGo Task (unpublished manuscript). 2007

Brooks A, Fulker DW, DeFries JC. Reading performance and general cognitive ability: a multivariate genetic analysis of twin data. Personal Individ Diff 1990;11:141-146.

Cardon LR, DiLalla LF, Plomin R, DeFries JC, Fulker D. Genetic correlations between reading performance and IQ in the Colorado Adoption Project. Intelligence 1990;14:245-257.

Cohen, RA.; Malloy, PF.; Jenkins, MA. Disorders of attention. In: Snyder, PJ.; Nussbaum, PD., editors. Clinical neuropsychology: a handbook for assessment. American Psychological Association; Washington, DC: 1998. p. 541-572.

Commodari E, Guarnera M. Attention and reading skills. Perceptual Motor Skills 2005;100:375-386.

Corkum PV, Siegel LS. Is the Continuous Performance Task a valuable research tool for use with children with attention-deficit-hyperactivity disorder? J Child Psychol Psych 1993;34:1217-1239.

Ehri LC, Wilce LS. Movement into reading: is the first stage of printed word learning visual or phonetic? Read Res Quarter 1985;18:47-65.

Fischer M, Barkley RA, Smallish L, Fletcher K. Executive functioning in hyperactive children as young adults: attention, inhibition, response perseveration, and the impact of comorbidity. Develop Neuropsychol 2005;27:107-133.

Gayan J, Olson RK. Genetic and environmental influences on individual differences in printed word recognition. J Experim Child Psychol 2003;84:97-123.

Gayan J, Olson RK. Genetic and environmental influences on orthographic and phonological skills in children with reading disabilities. Develop Neuropsychol 2001;20:483-507. 
Gayan J, Willcutt EG, Fisher SE, Francks C, Cardon LR, Olson RK, Pennington BF, Smith SD, Monaco AP, DeFries JC. Bivariate linkage scan for reading disability and attention-deficit/hyperactivity disorder localizes pleitropic loci. J Child Psychol Psych 2005;46:1045-1056.

Gillis JJ, Gilger JW, Pennington BF, DeFries JC. Attention deficit disorder in reading-disabled twins: evidence for a genetic etiology. J Abnorm Child Psychol 1992;20:303-315. [PubMed: 1377727]

Grigorenko EL. Developmental dyslexia: an update on genes, brains and environments. J Child Psychol Psych 2001;42:91-125.

Groot AS, de Sonneville LM, Stins JF, Boomsma DI. Familial influences on sustained attention and inhibition in preschoolers. J Child Psychol Psych 2004;45:306-314.

Halperin JM. The clinical assessment of attention. Intl J Neurosci 1991;58:171-182.

Hansen AL, Johnsen BH, Thayer JF. Vagal influence on working memory and attention. Intl J Psychophysiol 2003;48:263-274.

Harlaar N, Hayiou-Thomas ME, Plomin R. Reading and general cognitive ability: a multivariate analysis of 7-year-old twins. Sci Stud Read 2005;9:197-218.

Hayiou-Thomas ME, Harlaar N, Dale PS, Plomin R. Genetic and environmental mediation of the prediction from preschool language and nonverbal ability to 7-year reading. J Res Read 2006;29:50_ 74.

Heiser P, Heinzel-Gutenbrunner M, Frey J, Smidt J, Grabarkiewicz J, Friedel S, Kuhnau W, Schmidtke J, Remschmidt H, Hebebrand J. Twin study on heritability of activity, attention, and impulsivity as assessed by objective measures. J Attent Disord 2006;9:575-581.

Holmes J, Hever T, Hewitt L, Ball C, Taylor E, Rubia K, Thapar A. A pilot twin study of psychological measures of attention deficit hyperactivity disorder. Beha Genet 2002;32:389-395.

Kuntsi J, Eley TC, Taylor A, Hughes C, Asherson P, Caspi A, Moffitt TE. Co-occurrence of ADHD and low IQ has genetic origins. Amer J Med Genet B (Neuropsych Genet) 2004;124B:41-47.

Loo SK, Fisher SE, Francks C, Ogdie MN, MacPhie IL, Yang M, McCracken JT, McGough JJ, Nelson SF, Monaco AP, Smalley SL. Genome-wide scan of reading ability in affected sibling pairs with attention-deficit/hyperactivity disorder: unique and shared genetic effects. Mol Psych 2004;9:485493.

Neale, MC.; Boker, SM.; Xie, G.; Maes, HH. Mx: statistical modeling. 6. Box 980126 MCV, Richmond, VA 23298: 2003.

Olson R, Wise B, Conners F, Rack J, Filker D. Specific deficits in component reading and language skills: genetic and environmental influences. J Learn Disab 1989;22:339-348.

Plomin R, Craig I. Genetics, environment and cognitive abilities: review and work in progress towards a genome scan for quantitative trait locus associations using DNA pooling. Brit J Psych 2001;40 (suppl):s41-48.

Schulte-Korne G. Annotation: genetics of reading and spelling disorder. J Child Psychol Psych 2001;42:985-997.

Shaywitz SE, Escobar MD, Shaywitz BA, Fletcher JM, Makuch R. Evidence that dyslexia may represent the lower tail of a normal distribution of reading disability. New England J Med 1992;326:145-150. [PubMed: 1727544]

Sprenger-Charolles L, Siegel LS, Bonnet P. Reading and spelling acquisition in French: the role of phonological mediation and orthographic factors. J Experim Child Psychol 1998;68:134-165.

Swanson HL, Berninger VW. Individual differences in children's working memory and writing skill. J Experim Child Psychol 1996;63:358-385.

Tiu RD Jr, Wadsworth SJ, Olson RK, DeFries JC. Causal models of reading disability: a twin study. Twin Res 2004;7:275-283. [PubMed: 15193172]

Wagner, RK.; Torgesen, JK.; Rashotte, CA. The comprehensive test of phonological processing. PROED; Austin, TX: 1999.

Wagner RK, Torgesen JK, Rashotte CA, Hecht SA, Barker TA, Burgess SR, Donahue J, Garon T. Changing relations between phonological processing abilities and word-level reading as children develop from beginning to skilled readers: a 5-year longitudinal study. Develop Psychol 1997;33:468-479. 
Wainwright MA, Wright MJ, Geffen GM, Geffen LB, Luciano M, Martin NG. Genetic and environmental sources of covariance between reading tests used in neuropsychological assessment and IQ subtests. Behav Genet 2004;34:365-376. [PubMed: 15082934]

Wechsler, D. Wechsler abbreviated scale of intelligence. Psychological Corporation; New York: 1996.

Weiler MD, Bernstein JH, Bellinger D, Waber DP. Information processing deficits in children with attention-deficit/hyperactivity disorder, inattentive type, and children with reading disability. J Learn Disab 2002;35:448-461.

West RE, Stanovich KE. Source of inhibition in experiments on the effect of sentence context on word recognition. J Experim Psychol Learn Memory Cognit 1982;8:395-399.

Willcutt EG, Pennington BF. Comorbidity of reading disability and attention-deficit/hyperactivity disorder: differences by gender and subtype. J Learn Disab 2000;33:179-191.

Willcutt EG, Pennington BF, DeFries JC. Twin study of the etiology of comorbidity between reading disability and attention-deficit/hyperactivity disorder. Amer J Med Genet 2000;96:293-301. [PubMed: 10898903]

Willcutt EG, Pennington BF, Boada R, Ogline JS, Tunick RA, Chhabildas NA, Olson RK. A comparison of the cognitive deficits in reading disability and attention-deficit/hyperactivity disorder. $\mathrm{J}$ Abnorm Psychol 2001;110:157-172. [PubMed: 11261391]

Willcutt EG, Pennington BF, Olson RK, Chhabildas N, Hulslanger J. Neuropsychological analyses of comorbidity between reading disability and attention deficit hyperactivity disorder: in search of a common deficit. Develop Neuropsychol 2005;27:35-78.

Willcutt EG, Pennington BF, Smith SD, Cardon LR, Gayan J, Knopik VS, Olson RK, DeFries JC. Quantitative trait locus for reading disability on chromosome $6 \mathrm{p}$ is pleitropic for attention-deficit/ hyperactivity disorder. Amer J Med Genet 2002;114:260-268. [PubMed: 11920845]

Woodcock, RW.; Mather, N. Woodcock-Johnson tests of achievement. DLM Teaching Resources; Allen, TX: 1989. 


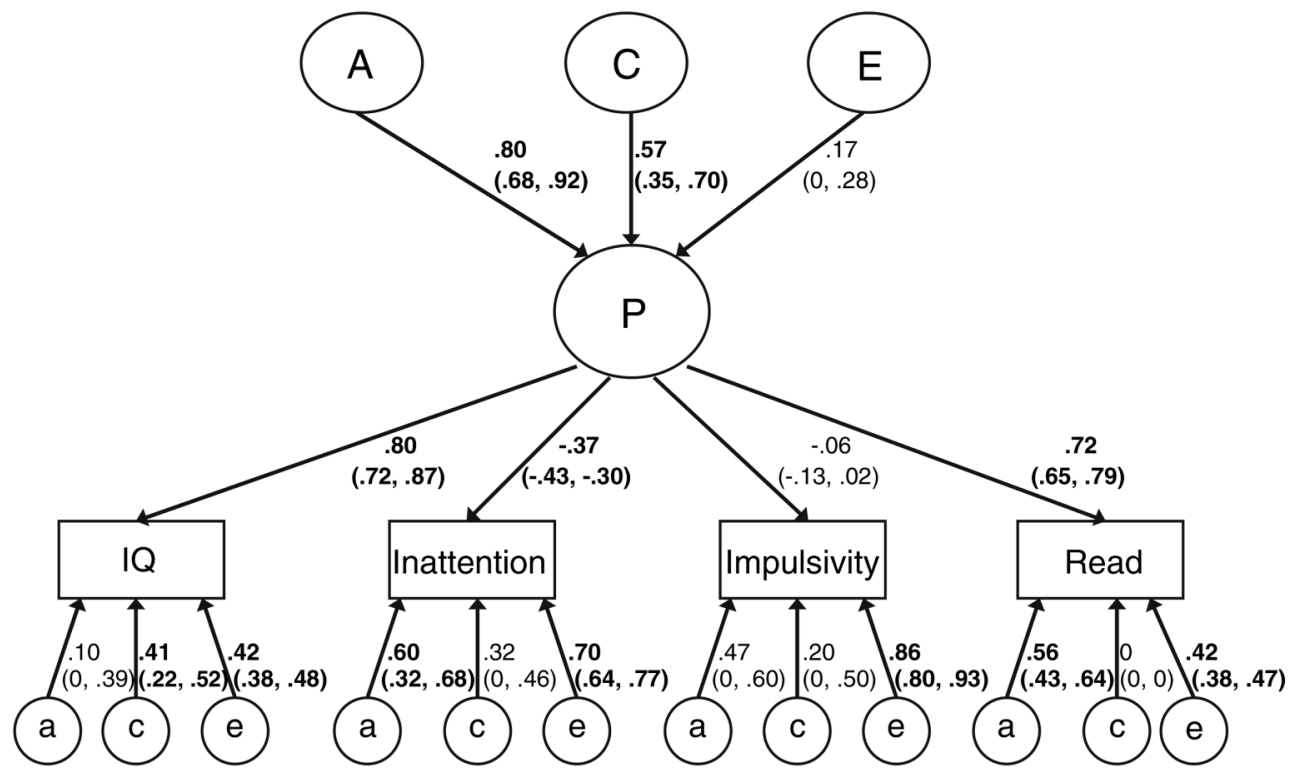

Fig 1.

Parameter estimates from the best-fitting one-common-factor model. Variability in each of the four measures, IQ, Inattention, Impulsivity, and Reading, is explained by specific genetic (a), shared environmental (c), and unique environmental (e) influences, as well common genetic (A), shared environmental (C), and unique environmental (E) influences that act through a latent common factor 


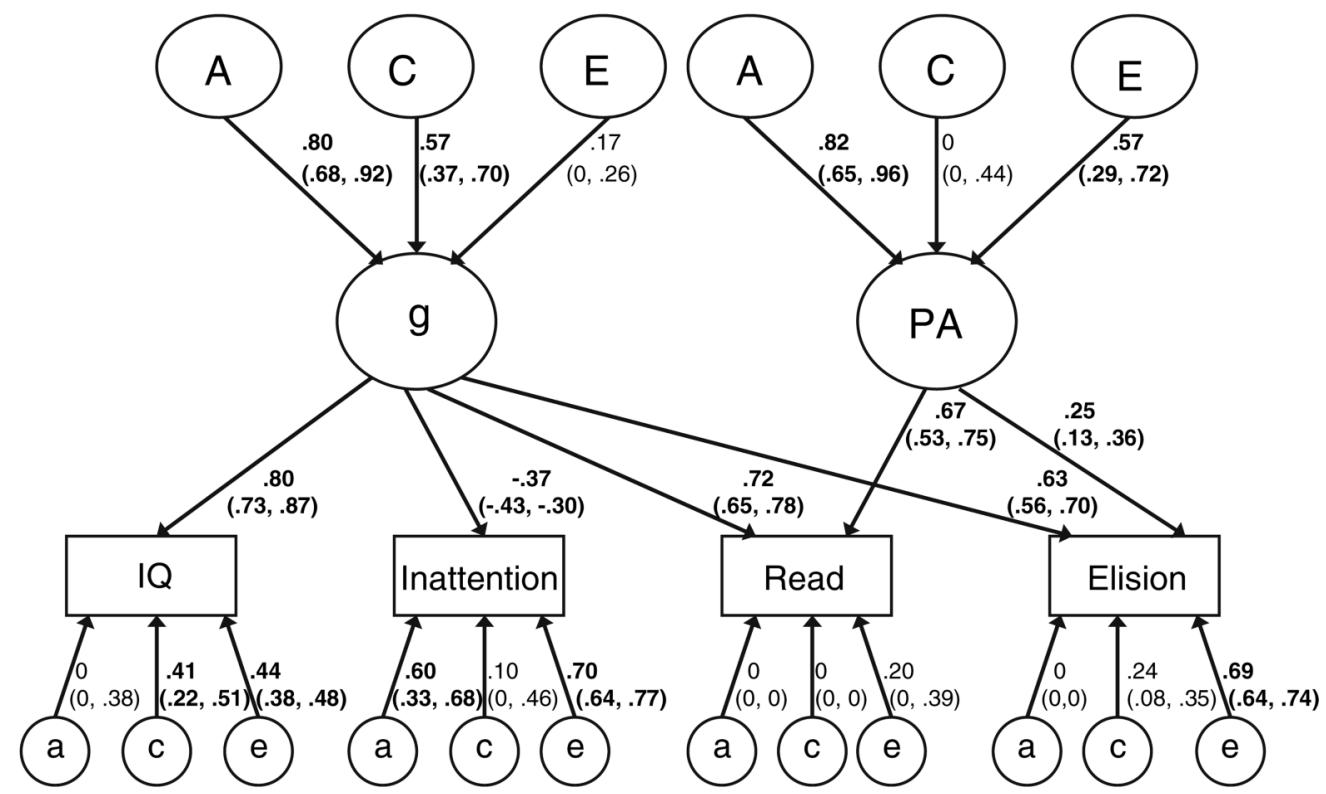

Fig 2.

Parameter estimates from the best-fitting two-common-factor model from the second set of analyses. The general cognitive ability factor, "g," receives contributions from genetic and common environmental influences and loads significantly on all four measures. The phonological awareness factor, "PA," receives contributions from genetic and unique environmental influences and loads significantly on only Reading and Elision 


\section{Table 1}

Correlations between measures

\begin{tabular}{lllll}
\hline & IQ & Inattention & Impulsivity & Reading \\
\hline Inattention & $-0.29^{*}$ & - & & - \\
Impulsivity & -0.03 & $0.07^{*}$ & -0.04 & - \\
Reading & $0.57^{* *}$ & $-0.26^{* *}$ & -0.03 & $0.61^{* *}$ \\
Elision & $0.49^{* *}$ & $-0.20^{* *}$ & \\
\hline
\end{tabular}

$$
\begin{aligned}
& * x<0.05 \\
& * * \\
& p<0.01
\end{aligned}
$$




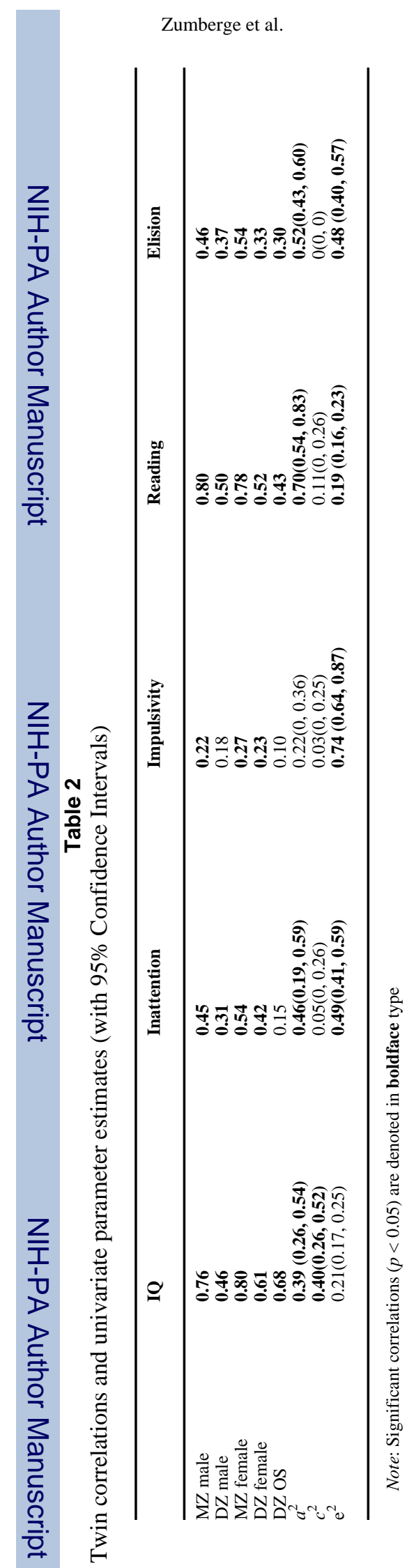

Page 15

Behav Genet. Author manuscript; available in PMC 2007 November 1. 


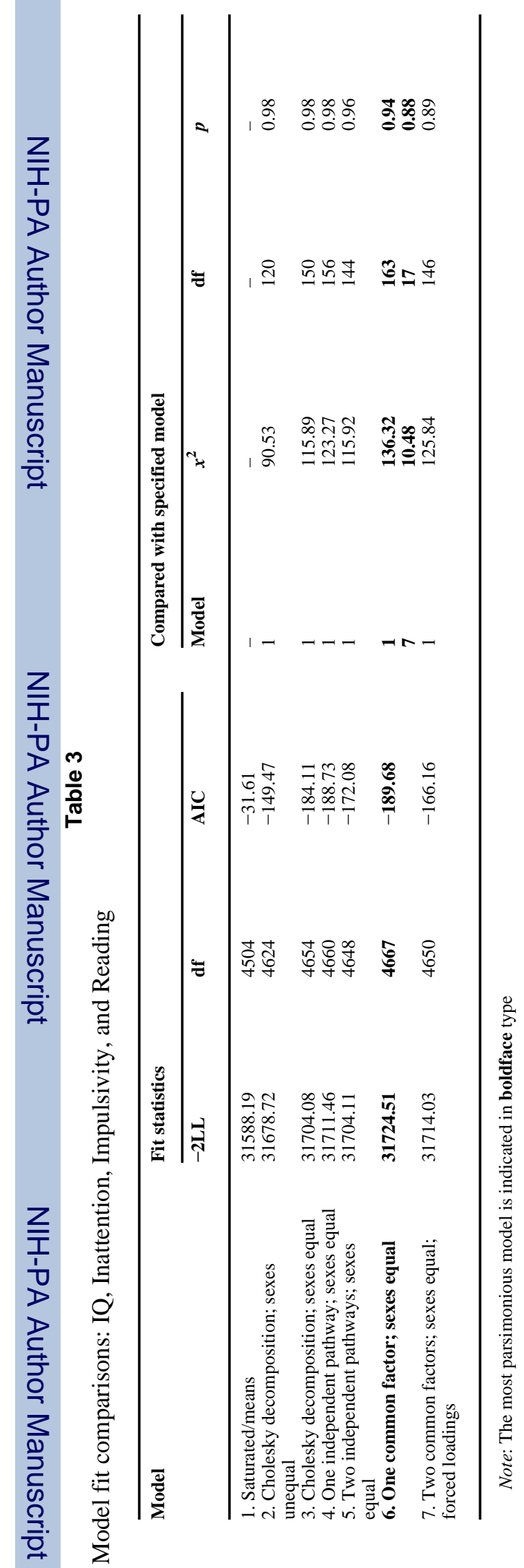




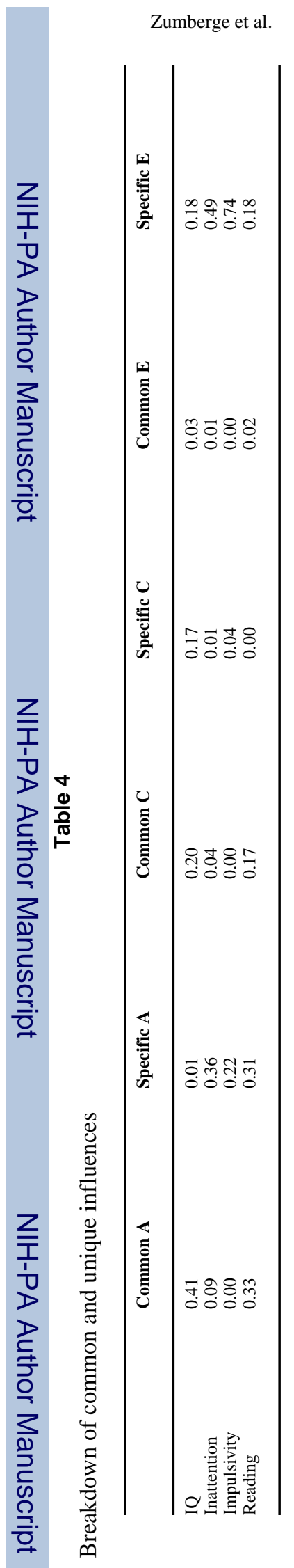

Page 17

Behav Genet. Author manuscript; available in PMC 2007 November 1. 


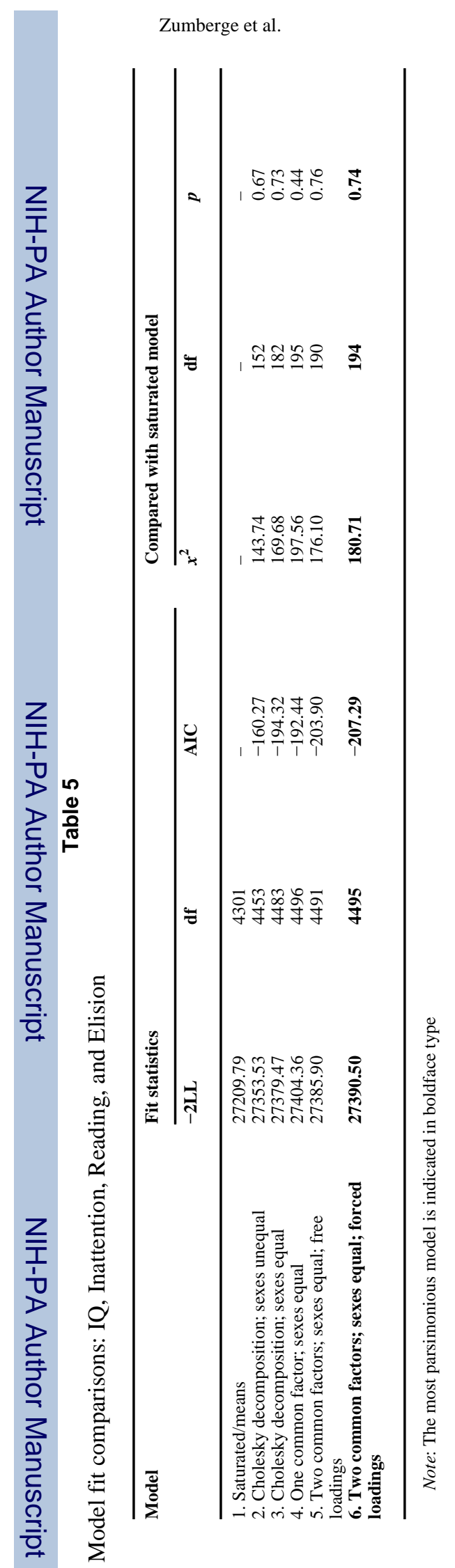

Behav Genet. Author manuscript; available in PMC 2007 November 1. 